\title{
Investigation the impact of outsourcing on competitive advantages' creation by considering Porter's model; Case study: Zamyad Company
}

\author{
Ahmad Reza Kasrai $^{a}$, Hassan Mehrmanesh ${ }^{\mathrm{a}}$ and Reza Ayazzade Shirazi ${ }^{\mathrm{b*}}$
}

${ }^{a}$ Department of Management, Central Branch, Islamic Azad University, Tehran, Iran

${ }^{b}$ M.A. in Operations Management, Central Branch, Islamic Azad University, Tehran, Iran

\begin{tabular}{|c|c|}
\hline ART I C LE I NFO & A B S T R A C T \\
\hline $\begin{array}{l}\text { Article history: } \\
\text { Received October 17, } 2011 \\
\text { Accepted } 12 \text { March } 2012 \\
\text { Available online } \\
\text { 16 March } 2012 \\
\text { Keywords: } \\
\text { Outsourcing } \\
\text { Competitive Advantages } \\
\text { Porter's Model } \\
\text { Cost Leadership Strategy } \\
\text { Differentiation Strategy } \\
\text { Segmentation Strategy }\end{array}$ & $\begin{array}{l}\text { Competitive advantage is an important factor in boosting companies' success and is considered } \\
\text { more emphatically in management and strategic marketing literature in recent years. There are } \\
\text { many different ideas about effective factors in creation of competitive advantages. Also fast } \\
\text { rate of change in business, is forcing CEOs to utilize some strategies, which have the best } \\
\text { impact on current organizational circumstances and the future trend of investigation in } \\
\text { organizational trades. Outsourcing is one of the best strategies, which are widely utilized by } \\
\text { CEOs in different organizations. Many managers believe that outsourcing is the solitary way } \\
\text { for preserving the balance of organization in } 21 \text { century. Based on Porter competitive advantage } \\
\text { model, there are three strategies, which lead a company to reach competitive advantage. These } \\
\text { strategies are cost leadership, differentiation strategy and segmentation strategy . } \\
\text { In this article, we are investigating outsourcing effects on creation of competitive advantages } \\
\text { through Porter model in an automotive factory in Iran. We design a questionnaire for gathering } \\
\text { necessary information about the role of outsourcing in creation of different strategies as } \\
\text { competitive advantages in managers' point of view. We analyze the questionnaires and } \\
\text { implement a goodness of fit test to recognize the distribution of data and the statistical method. } \\
\text { Preliminary results show that nonparametric statistic methods can be utilized for testing our } \\
\text { hypothesis. We use a Wilcoxon test to consider the null hypothesis and a Friedman test to } \\
\text { estimate the rank of means. Our findings verify an undeniable effect of outsourcing on creation } \\
\text { of competitive advantage and the ranking list is presented. }\end{array}$ \\
\hline
\end{tabular}

(c) 2012 Growing Science Ltd. All rights reserved.

\section{Introduction}

Organizations must represent a production in the competitive space of global economy and modern evolutionary world to not only satisfy their customers' needs but to maintain competitive prices. To create such competitive advantages, organizations are required to work hard on their product development and their capabilities.

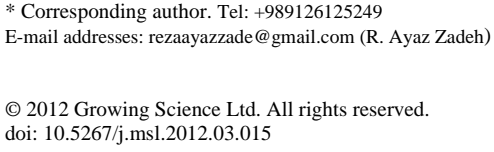


Auto industry is one of the most important multi billion dollars sectors of worlds' economy. This industry is ruled by many developed countries like Germany, United stated of America, Japan, South Korea and China. They have made a very competitive market through modern technology, specialized working force and outsourcing, which has made it difficult to compete with them. Outsourcing is one of the solutions, which could help organizations survive in such a tight competition. This study attempts to analyze the relationship between the implementation of outsourcing strategies and the achievement of gaining competitive advantages. The primary question is to know whether it is possible to gain competitive advantages by outsourcing or not. The proposed study of this paper attempts to address different issues associated with this type of question and understand how to handle it.

\section{Literature review}

\subsection{Outsourcing}

Outsourcing is not a new concept and has been used for many years and it has many different meanings. There are, however, several similar factors involved in its different meanings. The first common factor is that there is more than one group involved with the process of outsourcing. In fact, in outsourcing there are at least two groups where one group like A selects another group like B for outsourcing. The second factor is that the selected group (group B) does not belong to group A and it should be from another organization. The third factor is that group B should fulfill some activities for the group A. In a very fundamental form, outsourcing is said to the purchase some goods or services having been previously provided within organization (Goshal \& Bartlett, 1992).

Outsourcing is also defined as "utilization of other organizations' services and products in order to supply essential services and products of organization" or it is defined as "applying an extra center regarding operational administration that has been already committed within organization". In other words, this concept directly suggests usage of extra resources of organization, operational delegation and daily process of organizational management being devolutionary to a foreign provider (Lonsdale \& Cox, 2000). In fact, in delivery or outsourcing, organization advantages from knowledge, experience and innovation of providers of new services that have not been already utilized (D`Aveni, 1994). Another definition specifies outsourcing as "Outsourcing consists of delegating programming, management, administration and definite operations of activities to an independent organization (Phersson, 2001).

\subsection{Advantages of Outsourcing}

There are literally different advantages associated with outsourcing and some advantages of outsourcing strategy are as the following (Maelah et al. 2010):

1. Cost reduction: companies may emphasize on cost saving with different results such as unsuitableness, financial situation or profitability addition. Providing institutes of specialized services like providing centers of technical information services usually undertake such services with lower costs. When we use outsourcing, many unnecessary activities are eliminated and we may use outsourcing to get rid of many non-value added activities.

2. Increase in Productivity: The necessity to increase in productivity among employees is another reason considered in many organizations. Organizational managers of high levels usually focus on productivity in addition to other organizational' factors and do not pay special attention to supportive affairs such as keeping, repairing and administrative affairs. While providers are sensitive for supplying services and attend to productivity in their forces. Therefore, in order to increase their 
workforces' productivity, they continuously review and redesign their working methods and invest in this field.

3. Reduction in skillful workforces: company may find that skill and specialization of current employees are insufficient to commit some part of activities. This situation is possible to bring about reduction of improvement speed in activities. These problems can be removed by delegating such activities to people having necessary skills and specialization and being able to use specialization and experiences of individuals as well as advanced technologies.

4. Achievement to better management: Many firms may find that main activities being expected is not fulfilled and its reason is not just the lack of skill and specialization of employee, rather the problem is in administrating and managing activities, neglecting on time activities, manufacturing production and providing services with low quality. Hence, delegating activities to possess suitable skills can be suitable alternative. In these cases, administration and management of activities can be delegated to extra forces of organization.

5. Focus more on main activities and strategies: there are definite activities, which were the competitive advantage of organization and were more important from other cases. In the other words, managers of companies normally spend some part of their daily times for doing details of their working operations (occupational technical aspects). Assigning such activities to outside of organizations allows managers to focus more on the main activities of organization, which lead organizations to have better strategies to protect themselves from many possible threats.

6. Avoidance of major investment: Some activities may require significant amount of investment but the outcome may not be financially justifiable. Outsourcing helps significant reduction on the number of such activities.

7. Increase of flexibility: Increasing the flexibility is propounded while value of some activities is increased unexpectedly and employees are not able to do their task on time. Through delivering aforesaid activities in the organizations encountering such situations, fix costs associated with current employees of the company could be removed.

8. Improvement of performance assessment indexes: Some of companies delegate some part of their activities to other institutes to improve evaluative indexes of their performance. Delegating some of activities, this transfers some part of assets to other organization and increases output of assets.

9. Strengthening company validity: Companies can use outsourcing strategy to do some part of their activities as an instrument of marketing. Hence, they introduce resources of good providers and necessary services to their potential customers in addition to remark them. Therefore, some part of company activities are utilized by variable companies, customers can assure about goods' quality and provide services.

10. Protection of old activities: assessments in a company may show that actual employees are able to do coincident current activities of the company and accord with changes, if new technology is utilized. In such circumstances, delegating current activities to other people out of organization is the good solution in which management can make all the necessary attempts in order to adopt new ideas.

11. Performance improvement: In evaluation of activities, companies may find that the performance of some activities is not suitable or its cost is relatively high. In this case, management of company can remark actual employees or foreign forces of organization delegate activities to improve aforesaid activities. If so, these people can present suggestion including cost and quality of utilizing activity. Now, subsequent to evaluation of suggestion, management of company can protect company through fulfilling activities by employees, but the cost and the level of performance are determined on the basis of obtained information of suggestions. 


\subsection{Competitive advantage}

In this direction, there are several definitions, which are represented by experts. Competitive advantage is in addition of suggestive absorbs of company besides competitors with customers. According to Hätönen and Eriksson (2009), the competitive advantage of the differentiation in characteristics or dimension of each company is the ability of providing better services compared with what competitors offer to customers. Competitive advantage of providing values of company to customers is the values, which are higher than customers' costs (Porter, 1990). Competitive advantage idea was represented by Michel porter. He considered three questions in determining competitive advantage ideas (Porter, 1990):

1. Why a country is successful in international level of special industry?

2. How does a nation effect on competition of industries and industrial sections?

3. Why companies of a country select special strategy?

Different researchers and experts in the field of management and strategy have remarked patterns of obtaining competitive advantage, but in this field, Porter considered general guidance for making competitive advantage. General guidance is stabled in this principle that achievement to competitive advantage of central nucleus is the best marketing guidance. According to Porter, principle matter in competitive strategies is the comparative circumstances in related industry. He believes that this profitability and high performance is possible regarding adoption of general strategies production differentiation and leading in cost.

In cost leaderships, many firms attempt to produce and to supply standard productions to reduce cost prices of every unit for customer (everyone is sensitive towards price). The purpose of distinguishing production strategy is to supply productions and services being considered as individual production or services and distribute customers are not sensitive about the price. The purpose of segmentation is to attend productions and special services, which provide needs of small groups of consumers. The principle matter is whether we can achieve competitive advantage of utilizing outsourcing or not.

\section{Methodology}

\subsection{Aims of research}

The purpose of this research is to evaluate affecting outsourcing in fulfillment of competitive advantage in Zamyad Company. In addition, the secondary aims are to evaluate the effects of outsourcing in strategy of cost leadership, differentiation and segmentation in competitive advantage achievement in Zamyad Company.

\subsection{Statistical Hypothesis}

As explained, the main research hypothesis is as follows,

"Outsourcing is effective on creation of competitive advantages in Zamyad Company".

Also the secondary assumptions are:

First Hypothesis:

"Outsourcing is effective on strategy of cost leadership in order to make competitive advantage in Zamyad Company".

Second Hypothesis: 
"Outsourcing is effective on strategy of differentiation in order to make competitive advantage in Zamyad Company".

Third hypothesis:

"Outsourcing is effective on strategy of segmentation in order to make competitive advantage in Zamyad Company".

\subsection{Research Model}

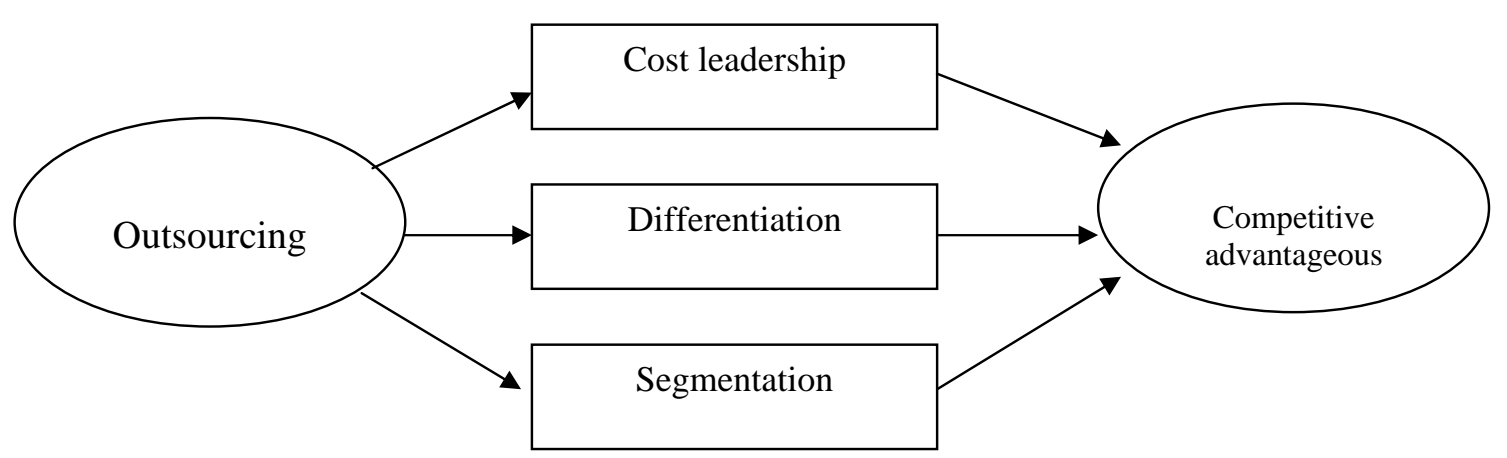

Fig.1. Research Model

\subsection{Research methodology}

Method of this research is descriptive and is formed as functional researches frame. Statistical population includes 40 experts that positioned in top level of Zamyad Company. A questionnaire is devised and implemented for data collection. Cronbach Alpha (Cronbach, 1951) method has been used for reliability test of questionnaire in this research. Statistic software of SPSS was used for accounted coefficient of Cronbach Alpha. Cronbach alpha for the main, first, second and third hypothesis are $0.825,0.721,0.758$ and 0.798 , respectively. These are relatively higher values and validated the questionnaire.

\section{Findings of research}

Subsequent to entering collected data in the software, we should apply goodness of fit test on data values to determine the data distribution. Collected results of Kolmogorov-Smironov are summarized in Table 1.

\section{Table 1}

Goodness of fit test result

\begin{tabular}{ccccc}
\hline Statistic & Main Hypothesis & $\begin{array}{c}\text { First } \\
\text { Hypothesis }\end{array}$ & $\begin{array}{c}\text { Second } \\
\text { Hypothesis }\end{array}$ & $\begin{array}{c}\text { Third } \\
\text { hypothesis }\end{array}$ \\
\hline Number & 40 & 40 & 40 & 40 \\
Mean & 3.83 & 3.65 & 3.61 & 3.50 \\
S.D. & 0.89 & 0.97 & 0.99 & 1.21 \\
Z Kolmogorov Smironov & 2.80 & 1.86 & 2.84 & 3.46 \\
The asymptotic probability & 0.000 & 0.002 & 0.000 & 0.000 \\
\hline
\end{tabular}

As we can observe from the results of Table 1, parametric statistic cannot be used for studying collected data and Kolmogorov-Smironov test rejects utilization of parametric statistic. So we have to use non-parametric tests for studying and evaluating collected data in this research. Several tests are accounted in the field of non-parametric statistic. We will utilize Wilcoxon test for evaluation of 
research assumptions. We used Wilcoxon test to assess our main and three other hypothesis in the research. The results are summarized in Table 2.

Table 2

Wilcoxon test result

\begin{tabular}{ccccc}
\hline Statistic & Main Hypothesis & $\begin{array}{c}\text { First } \\
\text { Hypothesis }\end{array}$ & $\begin{array}{c}\text { Second } \\
\text { Hypothesis }\end{array}$ & Third hypothesis \\
\hline Number & 40 & 40 & 40 & 40 \\
Estimated Median & 3.69 & 3.67 & 3.4 & 3.34 \\
Wilcoxon Statistics & 5.55429 & 5.48437 & 5.43832 & 4.43279 \\
The Probability & 0.000 & 0.000 & 0.000 & 0.000 \\
\hline
\end{tabular}

\subsection{Statistical Hypothesis}

According to the results gained from Table 2, assumptions are assessing as below:

Main Hypothesis is defined as:

$$
\left\{\begin{array}{l}
H_{0}: \bar{m}_{1} \leq 3 \\
H_{1}: \bar{m}_{1}>3
\end{array}\right.
$$

Based on the results gained from Table 2, the above null hypothesis is rejected. The amount of effectiveness of this factor regarding to estimated median is 3.69 and is between middle and high alternatives.

First Hypothesis is defined as:

$$
\left\{\begin{array}{l}
H_{0}: \bar{m}_{2} \leq 3 \\
\mathrm{H}_{1}: \overline{\mathrm{m}}_{2}>3
\end{array}\right.
$$

Based on the results gained from Table 2, the above null hypothesis is rejected. The amount of effectiveness of this factor regarding to estimated median is 3.67 and it's effective. It means outsourcing is effective on creation of cost leadership strategy in Zamyad Company.

Second Hypothesis is defined as:

$$
\left\{\begin{array}{l}
H_{0}: \bar{m}_{3} \leq 3 \\
\mathrm{H}_{1}: \overline{\mathrm{m}}_{3}>3
\end{array}\right.
$$

Based on the results gained from Table 2, the above null hypothesis is rejected. The amount of effectiveness of this factor regarding to estimated median is 3.4 and it's effective. It means outsourcing is effective on creation of differentiation strategy in Zamyad Company.

Third Hypothesis is defined as:

$$
\left\{\begin{array}{l}
H_{0}: \bar{m}_{4} \leq 3 \\
\mathrm{H}_{1}: \overline{\mathrm{m}}_{4}>3
\end{array}\right.
$$


Based on the results gained from Table 2, the above null hypothesis is rejected. The amount of effectiveness of this factor regarding to estimated median is 3.34 and it's effective. It means outsourcing is effective on creation of segmentation strategy in Zamyad Company.

\subsection{Prioritizing three strategies based on outsourcing impact}

For understanding the impact of outsourcing on three mentioned strategies in Porter's model, we use a ranking methodology. This prioritization will help decision makers know which strategy is affected more than other strategies in presence of outsourcing. Regarding the qualitative nature of data and measured variables, non-parametric statistic was used to compare three strategies. In Table 3, the results of Friedman test are shown.

Table 3

Friedman test result

\begin{tabular}{llll}
\hline Variable & Cost Leadership & Differentiation & Segmentation \\
\hline Ranks & 3.07 & 2.49 & 2.28 \\
\hline
\end{tabular}

According to the results of Friedman test, outsourcing has the most effect on strategy of reducing cost, differentiation and segmentation.

\section{Conclusion}

In this paper, we have presented an empirical study to find out the effects of outsourcing on auto industry. The proposed model of this paper designed a questionnaire and distributed among some top level managers who worked for one of the most active auto makers in Iran called Zamyad.

The results of the survey revealed that that outsourcing is effective on adopting competitive advantage of companies. Therefore, regarding comparably competitive space of home auto industries and attention to foreign automotive imports, we now understand the necessity of adopting competitive advantage. In the event that managers decided to make competitive advantage for their organization, they can use outsourcing. This important matter permits them to use concerned advantages of outsourcing and enjoy from competitive advantages.

\section{Acknowledgment}

The authors would like to thank the management team of Zamyad auto makers for patiently cooperating with us.

\section{References}

Barney, J.B. (1991). Firm Resources and Sustained Competitive Advantage. Journal of Management, 17(1), 99-120.

Barney, J.B. (1995). Looking inside for competitive Advantage. Academy of Management Cox Executive, 9 (4), 49-61.

Cronbach, L. J. (1951). Coefficient alpha and the internal structure of tests. Psychometrika, 16(3), 297-334.

D`Aveni, R.A. (1994). Hyper Competition: Managing the Dynamics Of strategic Maneuvering. The Free Press, New York, NY.

Ghoshal, S., \& Bartlett, C.A. (1992). Managing Across Borders. Random House, London.

Hamel, G., \& Prahlad, C.K. (1994). Competing for the Future. Tata Mgraw Hill.

Hätönen, J. \& Eriksson, T. (2009). 30+ years of research and practice of outsourcing exploring the past and anticipating the future. Journal of international management, 15(2), 142-155.

Hill, C.W \& L. Jones, G.R,( 1995). Strategic Management Theory. $1^{\text {st }}$ ed., Houghton Miff Line Company, U.S.A, p.102. 
Keegan, W. J. \& Green, M. S. (1997). Global Marketing. Prentice Hall.

Ma, H. (1999). Creation and Preemption for Competition Advantage. Management Decision. 37(3), 259-266.

Maelah, R., Aman, A., Hamzah, N., Amiruddin, R., \& Auzair, S.M. (2010). Accounting outsourcing turnback: process and issues. Strategic Outsourcing: An International Journal, 3(3), 226 - 245.

Miller, A. (1998). Strategic management. Prentice Hall, p.15.

Phersson, A. (2001). The strategic States model: Optimum strategies to reach high performance. management decision, 39(6), 441-447.

Porter, M. E. (1980). Competitive Strategy: Techniques for Analyzing Industries and Competitors. Free Press, New York.

Porter, M. E. (1990). The Competitive Advantage of Nations, New York: Free Press.

Porter, M. E. (1995). The Competitive Advantage of Nations, The Five Press, p.25.

Porter, M. E. (1998). Competitive Strategy, the Free Press. 